\title{
Practicing Hypothesis Report Testing- An Effort to Enhance the Learning in Design Analysis Laboratory
}

\author{
Nagaraj Ekabote ${ }^{1}$, Krishnaraja G Kodancha ${ }^{2}$, Deepak A Yaraguppi ${ }^{3}$ \\ KLE Technological University, BVB Campus, \\ Hubballi, India. \\ ${ }^{1}$ nagaraj_ekbote@bvb.edu \\ ${ }^{2}$ krishnaraja@bvb.edu \\ ${ }^{3}$ deepak.yaraguppi@bvb.edu
}

\begin{abstract}
Laboratory experiments are designed to develop the problem solving skills in students to bring research and practice culture. From the earlier reports, it has been found that running few but more open-ended experiments compared to exercises enhances the learning. Skills to execute open-ended experiments through mini lectures, additional reading material, tutorials or self-study are not greatly effective. To bridge this gap, an effort was made to practice hypothesis report testing before the conduction of open-ended experiment in Design Analysis (DA) lab. A hypothesis has been drawn from the journal paper and effort was directed to prove the hypothesis. The report format was designed with due emphasis on decision making in hypothesis report testing. Assessment was done through the rubrics set in accordance with ABET's 3b program outcome criteria. Authors witnessed improved proactiveness amongst students in executing the open-ended experiment, that lead to enhanced achievement of ABET's $3 \mathrm{~b}$ program outcome.
\end{abstract}

Keywords: Open-ended experiments, Hypothesis testing, Design Analysis lab.

\section{Introduction}

Today's engineering study is becoming more practical oriented compared to a decade before. Students are more interactive and needs hands on activities to learn the engineering concepts. Laboratories are ideal to imbibe the fundamental concepts by following a specific set of procedure prepared by the faculty. The contribution of laboratory experiments in understanding the fundamental

\section{Nagaraj Ekabote ${ }^{1}$}

KLE Technological University, BVB Campus, Hubballi, India.

${ }^{1}$ nagaraj_ekbote@bvb.edu concepts and developing the research skills in students are well known to everyone.

But the very objective of laboratory experiments is not met due to unconventional way of practicing experiments and wasn't assessing in a proper way. Most of the faculty, design the laboratory experiments to obtain closed form solutions by making students unable to explore the potential opportunities to develop the skills and knowledge required by Accreditation Board for Engineering and Technology, Inc. (ABET) program outcome 3b. ABET's 3b program outcome demands students to design and conduct experiments, as well as analyze and interpret data. Designing the laboratory experiments by students, needs indepth understanding of the fundamentals but having exposed only to conduction of experiments, the task may difficult. So a gradual change of practicing the laboratory experiments is a must to develop students in accordance with ABET's criteria.

\section{A. Literature Survey}

To teach effectively, faculty must have some strategy and selection of strategy bank on student's interest and their competency [1]. It is not only the strategy but the laboratory outcomes are heart of the laboratory sessions. By practicing the tailor made experiments lead to closed form solutions making students incapable of designing experiments. Lack of innovation in designing laboratory experiments by the faculty is another biggest concern. Susan S. Mathew \& Joshua Earnest [2] have proposed and implemented innovations like designing experiments, micro demonstrations etc. in most of the technical educational institutions in India. Such innovations gathered the student's attention towards the laboratory experiments. ABET mentioned specific program outcomes for graduate engineering students, in which $3 \mathrm{~b}$ program outcome majorly covered through laboratory experiments. Richard .M. Felder \& Rebecca Brent [3] given a highlight of attainment of program outcome $3 \mathrm{~b}$ through laboratory courses by running more open-ended experiments. In order to satisfy the program outcome $3 \mathrm{~b}$ through open-ended experiments 
demands certain skills and competency by the students. C. Anders R. Berg et al. [4] experimented open-ended inquiry problems in the laboratory and found the need of additional support for low attitude students. Joseph Tranquillo [5] has initiated a transformation of lab exercises from qualitative and quantitative to open-ended experiments for making students to confront practical problems after graduating. Lyle D. Feisel and Albert J. Rosa [6] have suggested the importance of objective based laboratory design to improve the enhancement of learning among students.

Most of the engineering faculty believe that to address the ABET's 3b criteria effectively, laboratory experiments must be modified and updated. It is not only by updating and buying new equipment will help this, but practicing experiments towards the program outcome and assessing for the same is needed. Consequently the challenge lies in making the effective laboratory syllabus, practice towards the research and assessment for continuous improvement. Some universities divide the laboratory experiments into four categories, namely: demonstration, exercises, structured enquiry and open-ended experiments. These categories were well defined in developing the student's skills. The ABET's program outcome $3 \mathrm{~b}$ elements can be well matched with these categories. Demonstration and exercises are helpful in acquiring the skills like conduction, obtaining required data and analyzing data. Open-ended experiments are ideal to give exposure of designing experiments for a given problem situation. Structured enquiry problems are developing the research skills in students by investigating a given problem.

\section{B. Objective of the Present Work}

In this paper an attempt is made to address following three issues associated with the laboratory.

a. The role of laboratory structure design in gradual skill development of students.

b. The inclusion of hypothesis testing as a structured enquiry problem in developing experiment design and research skills in students.

c. Assessment of students skills in accordance with the ABET's program outcome $3 \mathrm{~b}$.

\section{Methodology}

The structure for Design Analysis (DA) laboratory was modified to address all the categories of experiments. The weightage of marks for each category is given in Table 1. Depending upon the skills involved in executing each experiment, the laboratory sessions were allotted. DA lab was practiced for $6^{\text {th }}$ semester Automobile engineering students by using the ANSYS APDL software tool.

Table 1. Weightage among Lab Catogories

\begin{tabular}{|l|c|c|c|}
\hline \multicolumn{1}{|c|}{ Lab Category } & $\begin{array}{c}\text { Number of } \\
\text { Experiments }\end{array}$ & $\begin{array}{c}\text { Weightage } \\
(\%)\end{array}$ & $\begin{array}{c}\text { Number of } \\
\text { Sessions }\end{array}$ \\
\hline Demonstration & 01 & 5 & 1 \\
\hline Exercises & 05 & 55 & 7 \\
\hline Structured Enquiry & 01 & 20 & 2 \\
\hline
\end{tabular}

\begin{tabular}{|l|c|c|c|}
\hline Open-ended & 01 & 20 & 2 \\
\hline Total & $\mathbf{0 8}$ & $\mathbf{1 0 0}$ & $\mathbf{1 2}$ \\
\hline
\end{tabular}

The idea behind lab categorization was to develop skills for achieving all the outcome elements effectively. The complexity and the work required by the students in each exercise increases with moving to the next category.

Demonstration and exercises were individual activities and require fewer skills to execute. But structured enquiry and open-ended experiments involve cooperative learning to execute the solution. For these two categories a group of two members were created. Hypothesis testing has been introduced as structured enquiry. In hypothesis testing, a hypothesis report was provided to students and asked to investigate the hypothesis. Hypotheses used for the DA lab are given in Table 2. Hypotheses may be right or wrong, but emphasize was given on steps required to investigating the hypothesis through proper problem solving approach. Parameters such as width to height ratio (w/h), plate thickness (t), diameter of the hole (D) and applied load (P) were varied for each batch. Open ended experiment was at the end and it requires all the skills acquired during other category experiment execution. Analysis of any automotive component was set as an open-ended experiment.

Table 2. Hypotheses used in Design Analysis Laboratory

\begin{tabular}{|c|l|l|l|}
\hline Sl.No & \multicolumn{1}{|c|}{ Hypothesis } & Related figures \\
\hline 1 & $\begin{array}{l}\text { Stress Concentration is } \\
\text { going to reduce by } \\
\text { increase in thickness of the } \\
\text { rectangular plate. }\end{array}$ \\
2 & $\begin{array}{l}\text { Stress Concentration is } \\
\text { going to reduce on main } \\
\text { hole by the introduction of } \\
\text { two more auxiliary } \\
\text { elliptical holes as shown. }\end{array}$ \\
3 & $\begin{array}{l}\text { Stress concentration is } \\
\text { going to reduce on main } \\
\text { hole by introducing four } \\
\text { holes at certain angles and } \\
\text { at certain distance from the } \\
\text { main hole. }\end{array}$
\end{tabular}

Any activity without proper assessment will not quantify the learning. To align the skills obtained with program outcome $3 \mathrm{~b}$, a mapping has been done between program elements and hypothesis report testing experiment. Mapping is shown in Table 3.

Table 3. Mapping between Program Outcome 3b and Hypothesis Report Testing

\begin{tabular}{|c|c|c|}
\hline SI.No & $\begin{array}{c}\text { Program } \\
\text { Outcome } \\
\text { 3b elements }\end{array}$ & Elements of Hypothesis report testing \\
\hline 1 & $\begin{array}{l}\text { Desperimental design } \\
>\text { Choose experimental conditions [Free } \\
\text { body diagram and analysis type] }\end{array}$ \\
& $\begin{array}{l}\text { Experiments } \\
\text { Specify how many runs to carry out } \\
\text { for each condition [Validation process } \\
\text { and Convergence test] } \\
\text { The data to be collected [variables }\end{array}$ \\
\hline
\end{tabular}




\begin{tabular}{|c|l|l|}
\hline & & $\begin{array}{l}\text { and constraints deciding on which } \\
\text { results are of importance for analysis] } \\
>\text { Plan the data analysis to be carried out } \\
\text { [p method /h method] }\end{array}$ \\
\hline 2 & $\begin{array}{l}\text { Conducting } \\
\text { Experiments }\end{array}$ & $\begin{array}{l}\text { Running the experiment and collecting } \\
\text { the required data. }\end{array}$ \\
\hline 3 & $\begin{array}{l}\text { Analysing } \\
\text { and } \\
\text { Interpreting } \\
\text { data }\end{array}$ & $\begin{array}{l}\text { Interpretation of analysed data to draw } \\
\text { conclusions and submit the technical } \\
\text { report. }\end{array}$ \\
\hline
\end{tabular}

Rubrics were designed to measure the performance of students in hypothesis report testing and thus ensuring the attainment of program outcome. A sample of rubrics used for this activity is given in Table 4.

\section{Results \& Discussion}

Strategy was to master students in exploring each elements of open-ended experiment. It started with simple experiments to get familiarity with conduction of experiment

Table 4. Rubrics for Outcome Measurement

\begin{tabular}{|c|c|c|c|c|}
\hline \multirow{2}{*}{ Outcome } & \multicolumn{4}{|c|}{ Grades Distribution } \\
\hline & $100 \%$ & $75 \%$ & $50 \%$ & $25 \%$ \\
\hline $\begin{array}{c}\text { Ability to } \\
\text { examine } \\
\text { the data } \\
\text { and infer } \\
\text { the } \\
\text { results. }\end{array}$ & $\begin{array}{l}\text { Results } \\
\text { obtained } \\
\text { through } \\
\text { ANSYS } \\
\text { for } \\
\text { different } \\
\text { element } \\
\text { types and } \\
\text { for } \\
\text { different } \\
\text { mesh } \\
\text { density are } \\
\text { compared } \\
\text { through } \\
\text { theoretical } \\
\text { results to } \\
\text { conclude } \\
\text { the } \\
\text { experimen } \\
\text { t. }\end{array}$ & $\begin{array}{l}\text { Results } \\
\text { obtained } \\
\text { through } \\
\text { ANSYS } \\
\text { for } \\
\text { different } \\
\text { element } \\
\text { types and } \\
\text { for } \\
\text { different } \\
\text { mesh } \\
\text { density are } \\
\text { compared } \\
\text { through } \\
\text { theoretical } \\
\text { results but } \\
\text { unable to } \\
\text { conclude } \\
\text { the } \\
\text { experiment }\end{array}$ & $\begin{array}{l}\text { Results } \\
\text { obtained } \\
\text { through } \\
\text { ANSYS for } \\
\text { different } \\
\text { element } \\
\text { types or for } \\
\text { different } \\
\text { mesh } \\
\text { density are } \\
\text { compared } \\
\text { through } \\
\text { theoretical } \\
\text { results but } \\
\text { unable to } \\
\text { conclude } \\
\text { the } \\
\text { experiment. }\end{array}$ & $\begin{array}{l}\text { Results } \\
\text { obtained } \\
\text { only } \\
\text { through } \\
\text { ANSYS for } \\
\text { different } \\
\text { element } \\
\text { types or for } \\
\text { different } \\
\text { mesh } \\
\text { density are } \\
\text { not } \\
\text { compared } \\
\text { with theory. }\end{array}$ \\
\hline
\end{tabular}

and drawing conclusions based on results. After running few basic and fundamental experiments to get proficiency in ANSYS software, task was to handle hypothesis testing. For a hypothesis, a journal report [7] was given to refer and asked to prepare a problem solving approach for the same. Since format was provided to identify necessary steps of hypothesis testing, students utilized the format and came up with their problem solving approach.

Table 5. Format Submitted by Student's Team

\begin{tabular}{|l|l|}
\hline Team Number: 3 & Team Members: Tejas Das, Shrinivas \\
\hline \multicolumn{1}{|c|}{ Check points } & \multicolumn{1}{|c|}{ Answer } \\
\hline 1 Journal paper & Journal paper \\
\hline 2 Journal title & $\begin{array}{l}\text { the reduction of stress concentration in } \\
\text { a uni-axially loaded infinite width } \\
\text { rectangular isotropic/orthotropic plate } \\
\text { with central circular hole by coaxial }\end{array}$ \\
\hline
\end{tabular}

\begin{tabular}{|c|c|}
\hline & auxiliary holes \\
\hline $\begin{array}{l}3 \text { Software tool } \\
\text { used }\end{array}$ & ANSYS APDL \\
\hline $4 \mathrm{FBD} /$ model used & $\begin{array}{l}\text { Yes, 2-D model with Young's modulus } \\
\text { (E) \& Poisson's ratio }(\mu)\end{array}$ \\
\hline 5 Element Type & 8-node Quadrilateral element \\
\hline $\begin{array}{l}6 \text { Validation of } \\
\text { results }\end{array}$ & $\begin{array}{l}\text { Validation has been done through } \\
\text { theoretical calculations }\end{array}$ \\
\hline 7 Input data & $\begin{array}{l}\text { Yes given. Geometrical values, } \\
\text { material properties, applied load. } \\
\text { Variables: Diameter of the hole } \\
\text { Constraints: width, height and load }\end{array}$ \\
\hline $\begin{array}{l}8 \text { How many runs } \\
\text { carried out }\end{array}$ & Till the convergence obtained \\
\hline 9 Output data & $\begin{array}{l}\text { Maximum stress in the plate as well } \\
\text { Stress Concentration factor. }\end{array}$ \\
\hline 10 Conclusion & $\begin{array}{l}\text { Reduction in stress concentration, due } \\
\text { to introduction of co auxiliary holes. }\end{array}$ \\
\hline $\begin{array}{l}11 \text { How your } \\
\text { hypothesis will be } \\
\text { carried out } \\
\text { (problem solving } \\
\text { approach) }\end{array}$ & $\begin{array}{l}\text { Since our problem is thickness effect } \\
\text { on stress concentration, first we need to } \\
\text { justify 2D/3D analysis is required? } \\
\text { Validation can be used from current } \\
\text { journal paper. Thickness Considered } \\
\text { here are } 10 \mathrm{~mm}, 20 \mathrm{~mm} \text { and } 50 \mathrm{~mm} \text {. }\end{array}$ \\
\hline
\end{tabular}

A sample of format submitted by one of the student teams is given in Table 5. In each batch one hypothesis testing carried out by varying the geometrical parameters (variables) of a problem for each team. First session of the lab to read and understand the journal paper and present it in the format mentioned in the Table 5. In second session, students carried out experiment to check whether the hypothesis is right or wrong. Based on the results obtained, students draw the conclusions and interpreted the data. Finally students prepared a report by executing every elements of open-ended experiment and submitted the same.

The performance Indicators are measured through reports and viva-voce with certain weightage in marks as given in Table 6. At the end of each experiment the competency has been measured through viva and lab record.

Table 6. Measuring Method of Performance Indicators in Hypothesis Report Testing

\begin{tabular}{|l|c|l|}
\hline Indicators & $\begin{array}{l}\text { Weight } \\
\text { age } \\
\text { (Marks) }\end{array}$ & Measuring method \\
\hline $\begin{array}{l}\text { Minimizes data errors } \\
\text { based on results. }\end{array}$ & 2 & $\begin{array}{l}\text { Lab record \& viva: } \\
\text { Convergence criteria must } \\
\text { be demonstrated for the } \\
\text { results. }\end{array}$ \\
\hline $\begin{array}{l}\text { Ability to correlate the } \\
\text { measured parameter } \\
\text { and variables. }\end{array}$ & 2 & $\begin{array}{l}\text { Conclusion \& viva: } \\
\text { effect of change in } \\
\text { geometrical properties and } \\
\text { element properties on } \\
\text { results. }\end{array}$ \\
\hline $\begin{array}{l}\text { Ability to examine the } \\
\text { data and infer the } \\
\text { results. }\end{array}$ & 2 & $\begin{array}{l}\text { Results \& Viva: } \\
\text { Analytical solution to } \\
\text { justify the results } \\
\text { obtained. the }\end{array}$ \\
\hline $\begin{array}{l}\text { Ability to provide } \\
\text { content that is factually } \\
\text { correct, supported with } \\
\text { evidence, explained } \\
\text { with sufficient detail, }\end{array}$ & 4 & $\begin{array}{l}\text { Lab record: A defined } \\
\text { procedure to perform } \\
\text { experiment and thus } \\
\text { repeated. }\end{array}$ \\
\hline
\end{tabular}




\begin{tabular}{|c|c|c|}
\hline $\begin{array}{ll}\text { and } & \text { properly } \\
\text { documented. } & \\
\end{array}$ & & \\
\hline $\begin{array}{l}\text { Use software and } \\
\text { computer simulations } \\
\text { for system/process } \\
\text { design, modeling and } \\
\text { convergence criteria. }\end{array}$ & 2 & $\begin{array}{l}\text { Lab record \& Viva: } \\
\text { Demonstrating the } \\
\text { procedure of conducting } \\
\text { the experiment. }\end{array}$ \\
\hline
\end{tabular}

After assessing and allotting marks as per grades distribution, the final marks distribution among students for hypothesis report testing was compared with students' performances of earlier experiments. Comparison is given in Table 7. From the data, it is clear that an improvement in executing the task was seen in hypothesis report testing. Average students' performance was the key in this task and they imbibed the skills of executing the open-ended experiment.

The gap where the students were lacking in executing the hypothesis testing was identified and a tutorial session held to cover the same. In tutorial emphasis was given on conclusion extraction from obtained results. Since most of the students obtained correct results but unable to

Table 7. Comparison of Students Performances

\begin{tabular}{|c|c|c|}
\hline $\begin{array}{c}\text { Category (Marks in } \\
\text { \%) }\end{array}$ & $\begin{array}{c}\text { Students in } \\
\text { earlier } \\
\text { experiments }\end{array}$ & $\begin{array}{c}\text { Students in } \\
\text { Hypothesis report } \\
\text { testing }\end{array}$ \\
\hline Good (90\%-100\%) & 11 & 21 \\
\hline Average (60\%-90\%) & 31 & 29 \\
\hline $\begin{array}{c}\text { Below Average } \\
\text { (Below 60\%) }\end{array}$ & 12 & 04 \\
\hline
\end{tabular}

interpret them and draw the conclusions. Even drawing a hypothesis from a report was highlighted in the tutorial. Once it was made sure that every aspect of hypothesis report testing addressed, students allowed for taking open-ended experiment. To quantify the effect of hypothesis report testing over open-ended experiment has been measured. Particularly the experiment design element in open-ended experiment was the crucial part. Students' performance in open-ended experiment was compared with the previous year performance for the same lab and is given in Table 8 .

Table 8. Students Marks Distribution in Open-Ended Experiment

\begin{tabular}{|c|c|c|c|c|c|c|c|c|}
\hline \multirow{3}{*}{$\begin{array}{c}\text { Marks } \\
(\%)\end{array}$} & \multicolumn{8}{|c|}{ Elements of Open-ended experiment } \\
\hline & \multicolumn{2}{|c|}{ Design } & \multicolumn{2}{|c|}{ Conduct } & \multicolumn{2}{|c|}{ Analysis } & \multicolumn{2}{|c|}{ Interpret } \\
\hline & $\begin{array}{l}2013 \\
-14\end{array}$ & $\begin{array}{l}2014 \\
-15\end{array}$ & $\begin{array}{l}201 \\
3-14\end{array}$ & $\begin{array}{l}201 \\
4-15\end{array}$ & $\begin{array}{l}201 \\
3-14\end{array}$ & $\begin{array}{l}201 \\
4-15\end{array}$ & $\begin{array}{l}201 \\
3-14\end{array}$ & $\begin{array}{l}201 \\
4-15\end{array}$ \\
\hline $90-100$ & 00 & 17 & 14 & 39 & 12 & 26 & 02 & 25 \\
\hline $75-89$ & 00 & 25 & 25 & 13 & 23 & 20 & 08 & 18 \\
\hline $60-74$ & 14 & 08 & 08 & 02 & 10 & 06 & 21 & 06 \\
\hline $40-59$ & 12 & 04 & 01 & 00 & 15 & 02 & 11 & 05 \\
\hline $0-39$ & 36 & 00 & 04 & 00 & 02 & 00 & 10 & 00 \\
\hline
\end{tabular}

Student's performance between two successive academic batches shows the progress in executing the openended experiment. In 2013-14 academic batches, the experimental design and interpretation of the obtained results were not satisfactory, since few of the students only obtained $90 \%-100 \%$ of marks in that category. In 2014-15 academic batches all the elements of open-ended experiment achievement was considerably improved. The current results indicate the significance and role of hypothesis report testing activity in executing the open-ended experiment.

\section{Conclusion}

Earlier, Authors efforts by giving mini lectures, hand books, tutorials were not that effective in improving the skills of executing the open-ended experiment. The initiative of replicating the same results of journal paper was also not that effective, since it restrict the freedom of taking research activity. Hypothesis report testing proved a better activity to be considered to address research as well as practice culture by satisfying the ABET's 3b program outcome. The major findings in this work are outlined as follows:

1) A comparison of students' performance in each category of experiments indicates that gradual enhancement of students' skills, which is attributed to the laboratory structure design.

2) Student's cognitive levels enhanced in the designing of experiments, earlier which was missing in practicing of open-ended experiments.

3) Hypothesis report testing appeared as an effective prerequisite for execution of open-ended experiment.

4) Journal paper investigations lead students to develop research and practice culture in problem solving.

\section{Acknowledgment}

Authors gratefully acknowledge the support by beloved Students, Faculty, Principal, Vice chancellor and Management of KLE Technological University, BVB Campus, Hubballi, Karnataka.

\section{References}

[1] Teaching Assistant Fellows, (1995) " Strategies for Effective Teaching a handbook for Teaching Assistants," Journal of Engineering Education, University of WisconsinMadison, College of Engg.

[2] Susan S. Mathew, Joshua Earnest., (2004) "LaboratoryBased Innovative Approaches for Competence Development," Global Journal of Engineering. Education, Vol.8, No.2.

[3] Richard M. Felder \& Rebecca Brent., (2003) "Designing and Teaching Courses to Satisfy the ABET Engineering Criteria," Journal of Engineering Education, 92 (1), 7-25.

[4] C. Anders R. Berg et al., (2003) "Benefitting from an open-ended experiment? A comparison of attitudes to, and outcomes of, an expository versus an open-inquiry version of the same experiment," International journal of science education, ISSN 1464-5289 online Taylor \& Francis Ltd.

[5] Joseph Tranquillo., (2006) "Qualitative, quantitative, open-ended: a progression in laboratory/lecture learning," 
Proceedings of the American Society for Engineering Education Annual Conference and Exposition.

[6] Lyle D. Feisel and Albert J. Rosa, (2005) "The Role of the Laboratory in Undergraduate Engineering Education," Journal of Engineering Education, January, 121-130.
[7] Jain N.K., (2011)"The Reduction of Stress Concentration in a Uni-Axially Loaded Infinite Width Rectangular Isotropic/Orthotropic Plate with Central Circular Hole by Coaxial Auxiliary Holes," IIUM Engineering Journal, Special Issue in Science and Ethics, Vol. 